\title{
SEGURIDAD ALIMENTARIA, DESARROLLO RURAL SOSTENIBLE Y EQUIDAD DE GÉNERO EN LA HERENCIA DE LA TIERRA
}

\author{
ALIMENTARY SECURITY, DEVELOP RURAL SUSTAINABLE AND GENDER \\ JUSTNESS IN THE INHERITANCE OF THE LAND
}

Rolando Pavó Acosta*

\begin{abstract}
Resumen
La presente exposición constituye un nuevo cuestionamiento sobre las reglas de la herencia de la tierra, proponiéndose determinar en qué medida el Derecho Agrario vigente en Cuba satisface los presupuestos de justicia y equidad de género al establecer las reglas sobre la herencia de la tierra y demás bienes agropecuarios en caso de que el fallecido haya sido pequeño agricultor, y propone los cambios legislativos que resultan pertinentes en ese ámbito jurídico a los fines de lograr la seguridad alimentaria, el desarrollo agrícola y el desarrollo rural sostenible.
\end{abstract}

Palabras clave: Herencia de la tierra. Equidad de género. Seguridad alimentaria. Desarrollo agrícola. Desarrollo rural sostenible.

\begin{abstract}
The present work constitutes a new question on the rules of the inheritance of the effective earth, intending to determine the effective Agrarian Law in Cuba satisfies the budgets of justice and gender justness when establishing the rules on the inheritance of the land and other agricultural goods in what measure in case the deceased has been small farmer, and it proposes the legislative changes that are pertinent in that juridical environment to the ends of achieving the alimentary security, the agricultural development and the sustainable rural development.
\end{abstract}

Words key: Inheritance of the earth. Gender justness. Alimentary security. I develop agricultural. Develop rural sustainable.

\section{Introducción:}

No vayas a enseñar este libro al cura de tu pueblo: porque a él le interesa mantenerte en la oscuridad; para que todo tengas que ir a preguntárselo a él. Y como él te cobra por echar agua en la cabeza de tu hijo, por decir que eres el marido de tu mujer, cosa que ya tú sabes desde que la quieres y te quiere ella. (PÉREZ, J., 1975, p.381)

Como ya se ha argumentado anteriormente el error y la injusticia en la solución de los conflictos agrarios recaídos en la propiedad, posesión y herencia de la tierra y demás bienes agropecuarios suelen traer aparejados, la improductividad o deficiente aprovechamiento de la tierra, daños o pérdidas a las producciones y cosechas, y no son

\footnotetext{
* Doctor en Ciencias Jurídicas, Profesor de la Facultad de Derecho, Universidad de Oriente, Santiago de Cuba.
} 
despreciables las afectaciones que pudieran acarrearse en el disfrute de los derechos fundamentales de los trabajadores del campo, resultando incuestionable que ello también puede tener impactos en el estado de las relaciones familiares e interpersonales, y en la conciencia jurídica y la cultura jurídica de parte importante de la población, pudiendo derivarse también lógicas repercusiones políticas (ACOSTA, 1997, 2011).

Por tales razones, resulta forzoso compartir el criterio del ilustre maestro del Derecho Agrario Ricardo Zeledón Zeledón cuando declara que la mayor aspiración del Derecho Agrario es la de contribuir a la consolidación de la paz entre los seres humanos y los pueblos, convertirse en un verdadero derecho para la paz, llevarla a las complejas relaciones de convivencia económica y social; porque en ese complejo mundo las personas tienen formas de vida entrelazadas a su propia historia y cultura, donde es frecuente el conflicto y el enfrentamiento, incluso nace y se desarrolla la guerra (ZELEDÓN, 2011, p.38).

El Derecho Agrario latinoamericano, en consonancia con las demandas de diversas organizaciones sociales, en las últimas décadas, ha actualizado el planteamiento de sus fines asumiendo en tal sentido a la seguridad alimentaria, la soberanía alimentaria y el desarrollo rural sostenible, en consecuencia, ha propugnado la necesidad de imponer reglas sobre la herencia de la tierra y en la transmisión del usufructo más acordes con la realidad social y con los roles que ha estado desempeñando la mujer en los sistemas productivos, a consecuencia de problemas como: los conflictos armados en el medio rural, con su secuela de muerte, mutilación y desaparición de miles de habitantes, sobre todo los hombres, lo cual ha generado desequilibrios en la estructura demográfica, que se manifiestan en la desproporción entre hombres y mujeres, la carencia de fuerza de trabajo masculina; similares efectos han tenido en esa situación la sostenida migración externa e interna.

En el caso de Cuba, existen estudios que han mostrado la existencia de problemas demográficos como el éxodo rural, acumulado durante décadas, el cual es señalado como causa y a la vez efecto del desempeño desfavorable del sector agropecuario y del déficit en el desarrollo rural. En 1981, había 9723605 habitantes y de ellos 6712030 vivían en zona urbana y 3011575 en zonas rurales, para un 69,1 y 30.9\% respectivamente, en el 2010 conforme a datos de la Oficina Nacional de Estadística (ONE) Cuba cerró con una población de 11241161 habitantes, de esa cifra, el 75\% residían en zonas urbanas, para un total de 8 465 730, mientras apenas 2775 431, o sea el 24,6 \% vivían en áreas rurales ${ }^{1}$. Un problema asociado al éxodo rural, es el de la deficiente composición estructural por edades y por sexos

\footnotetext{
${ }^{1}$ Ver Anuario Estadístico de Cuba. 1986, p.58, y ver NOTIMEX: La Habana, 6 de abril de 2011, en Red Jurídica 7 de abril de 2011.
}

R. Fac. Dir. UFG, v. 37, n. 2, p. 259 - 281, jul. / dez. 2013 
en el medio rural (CABRERA, 2008, p.7). Si en 1990 los jóvenes significaban el 34,2\% de los habitantes rurales, en el 2002 sólo representaban el 24,7\%, en tanto que las personas de 60 y más años ascendieron del 8,7\% al 11,5\% (RÉMON, 2006, p.61), esa disminución total de habitantes del campo se ha manifestado de manera acentuada en esas dos dimensiones; más proporción de personas del sexo femenino y de la tercera edad.

A este respecto, resulta coherente la propuesta del maestro Zeledón de fundar un Derecho Agrario profundamente equitativo, con la inteligencia suficiente para introducir fórmulas jurídicas dirigidas a impregnar un sello de justicia para el sector agrario, reivindicar la condición de la mujer en el proceso productivo, impedir la discriminación, por cualquier razón, en el acceso a los medios de producción, promover la dignidad de los jóvenes así como el respeto a los ancianos sin posibilidades de trabajar, en fin imprimir un sello social al sistema económico y productivo agrario. Esto es, un derecho equitativo para encontrar, desarrollar y garantizar la paz (ZELEDÓN, 1999, p.4).

Para los cubanos, resultan incontestables los logros alcanzados en las últimas décadas en la lucha por la plena igualdad de la mujer y particularmente en el ámbito de la comunidad rural, donde ha sido más difícil el avance. No obstante, se presentan disfuncionalidades en el sistema jurídico de las que evidentemente resultan afectaciones al derecho de la mujer a la tierra y consecuentemente la equidad de género en el ámbito de la vida rural, ${ }^{2}$ las cuales precisan de atención interdisciplinaria por parte de las Ciencias Sociales.

La presente exposición constituye un nuevo cuestionamiento sobre las reglas de la herencia de la tierra vigentes en Cuba, proponiéndose determinar en qué medida el Derecho Agrario vigente en Cuba satisface los presupuestos de justicia y equidad de género al establecer las reglas sobre la herencia de la tierra y demás bienes agropecuarios en caso de que el fallecido haya sido pequeño agricultor, arribando a posibles respuestas sobre la cuestión sobre si: se trata de deficiencias en el Derecho vigente o deficiencias en la actividad interpretativa de los operadores administrativos del Derecho Agrario?, y en consecuencia si se requiere de modificaciones de la legislación cubana vigente o si bastaría con cambiar los conocimientos y percepciones de los que interpretan y aplican tales normas?

\footnotetext{
${ }^{2}$ El presente trabajo puede apreciarse como un reanálisis de las reglas que fijan el régimen especial de la herencia de la tierra y demás bienes agropecuarios, desde la perspectiva de género, y por tanto tiene claros antecedentes en trabajos propios como: Mecanismo y procedimientos de solución de conflictos agrarios (Tesis de Doctorado), "El derecho de la mujer, a la tierra entre la igualdad y la discriminación", La Justicia Agraria y sus desafios.
}

R. Fac. Dir. UFG, v. 37, n. 2, p. 259 - 281, jul. / dez. 2013

ISSN 0101-7187 


\title{
1 Los presupuestos jurídicos de la justicia y equidad de género en el ámbito de la propiedad y herencia de tierras y bienes agropecuarios
}

\begin{abstract}
Los primeros grandes desafíos de la ciencia del Derecho Agrario indudablemente se encuentran vinculados con la labor sistemática, constructiva y metodológica, en un encuentro del Derecho Agrario consigo mismo, para distinguirse externamente e identificarse internamente. (ZELEDÓN, 2000, p.11)
\end{abstract}

Existe consenso en la doctrina de los agraristas en que sólo a través del estudio técnico y creación jurídica independiente a partir de los conceptos, teorías y principios propios del Derecho Agrario, es que pueden lograrse los propósitos de: asegurar los fines de las normas jurídicas agrarias, y corregir los defectos existentes (lagunas, colisiones y otras deficiencias técnicas) y establecer un orden armónico y sistematizado.

Por otra parte, admitiendo que se trata de una rama jurídica que debe resultar más de justicia que de legalidad estricta -lo cual la distingue de otras como el Derecho Civil-, entonces la argumentación, interpretación y aplicación de sus reglas no puede reducirse a la juridicidad del discurso contenido en la normas de Derecho Agrario positivo, sino que debe extenderse a sus principios y por tanto, a otros condicionantes económicos, políticos, sociales, culturales, éticos, filosóficos, y de otros órdenes.

El profesor Ricardo Zeledón Zeledón, ha revelado que los factores que permitieron el origen del moderno Derecho Agrario fueron: el capitalismo, la ruptura de la unidad del Derecho Privado, y la evolución del esquema jurídico constitucional (ZELEDÓN, 1987, p.49). Por tanto vale subrayar, que se trata de una nueva rama legislativa, que en consonancia con los principios teleológicos que la orientan, tanto en lo sustantivo como en lo procesal, incorpora nuevas instituciones no conocidas por otras materias, al mismo tiempo que modifica el carácter de otras instituciones ya conocidas, las innova, las flexibiliza.

Siguiendo este curso del análisis, expresaría el ya citado Ricardo Zeledón Zeledón (1987, p.42) que, "El Derecho Agrario nace del Derecho Civil, pero no es Civil, pues éste es más Derecho de Propiedad, mientras el Derecho Agrario es Derecho de actividad". A este respecto no resulta ocioso subrayar la relación de supletoriedad en que se encuentran las normas del Código Civil respecto al Derecho Agrario, en el plano sustantivo. ${ }^{3}$

\footnotetext{
${ }^{3}$ El artículo 8 del Código Civil Cubano, Ley 59 de 1987, dispone que "Las disposiciones de este Código son supletorias respecto a materias civiles u otras reguladas en leyes especiales", y en ese mismo sentido la Disposición Final Primera establece que, "Sin perjuicio del carácter supletorio de este Código, se rigen por la legislación especial las relaciones jurídicas relativas a la familia; los descubrimientos, inventos, innovaciones, racionalizaciones, creación de obras científicas, educacionales, literarias y artísticas; la caza y la pesca; los
} 
En el ámbito del Derecho Procesal Agrario, vale la pena significar cómo la necesidad de satisfacer objetivos de justicia social en el ámbito rural entra en pugna con los principios e instituciones típicas del proceso civil ordinario, por tanto se produce una necesidad de superación de cierta rigidez de lo procesos civiles ordinarios, derivados del imperio del principio de legalidad, y de sustitución de perniciosos hábitos procedimentales derivados de una idiosincrasia individualista propia de las personas en conflicto ante un juez ordinario, por una actitud inspirada en valores sociales de acuerdo con el modo de ser del Derecho Agrario (ACOSTA, 2011, p.36-37).

Nadie debería dudar que el derecho a la tierra constituya el derecho humano esencial de los habitantes del campo y la base del desarrollo rural y del desarrollo agrícola sostenible. Sin embargo cuando se alude a los derechos humanos, habitualmente se piensa en el hombre de la ciudad y cuando se escribe acerca del principio de equidad de géneros, se hace refiriéndose principalmente a la igualdad en el empleo, en la educación, en la promoción social, en la promoción política y otros aspectos; pero escasamente se aprecia el asunto desde la perspectiva del derecho socioeconómico esencial que tienen los campesinos, que es el derecho a la tierra.

La supresión o atenuación de las aludidas desigualdades e inequidades ha sido propósito declarado en múltiples doctrinas políticas y sociales; pero aunque mucho ha avanzado la humanidad en materia de leyes encaminadas a asegurar ese principio, según muestran diversos estudios empíricos, se ha logrado solo una parcial solución de tales necesidades en los distintos países, debido a que en verdad se trata de un fenómeno de extrema complejidad dada la mixtura de factores económicos, políticos, sociales, culturales que son determinantes.

Algunos de tales factores son de naturaleza subjetiva, pues las leyes y su realización están mediadas a menudo por los prejuicios, la cultura y la moral de la época, las motivaciones e intereses, declarados, incluso inconscientes de las personas que intervienen en los procesos de aplicación de las normas, como dijera hace ya más de un siglo el conocido juez norteamericano Oliver W. Holmes en su célebre disertación acerca del Common Law (HOMES apud HABBA, 1990, p.230-231).

Este hecho hace que, por ejemplo, siendo más las veces que son personas del sexo masculino los que imparten la justicia, en muchos ámbitos, entonces puede suceder que los criterios de interpretación de las normas sustantivas tengan signos claros del género posesión, propiedad y herencia de la tierra y demás bienes destinados a la producción agropecuaria y forestal...". 
masculino y que particularmente puedan ser indebidamente desfavorables a la justicia y a la equidad de género ${ }^{4}$.

Por el derecho a la tierra, se debe entender, el derecho subjetivo, a ser sujeto de la propiedad individual o colectiva sobre la tierra, a obtener su adjudicación en concepto de propietario, o en el de usufructo y a ejercer cuantas acciones sean pertinentes para obtenerla y conservarla. A este respecto, vale la pena destacar que se aprecia como regularidad el hecho de que en las leyes de reforma agraria dictadas en los países de nuestro ámbito continental se habla de los beneficiarios o sujetos del derecho a las adjudicaciones de tierra utilizando términos generales desde el punto de vista de género, aludiendo indistintamente a: "el hombre que la trabaja", "individuos o agricultores" como en los artículos 1 y 2, ambos de la ley venezolana, " "persona natural”, como en la Ley boliviana de $1996 .{ }^{6}$

Según estudios publicados por la FAO, “Aspectos culturales, jurídicos e institucionales limitan el acceso de la mujer a la tierra es decir, tienden a privarla del derecho de propiedad o explotación del recurso. La lentitud e ineficiencia en los trámites de regularización de la tenencia, incluida la titulación y la falta de apoyo financiero y de asistencia técnica adecuada y oportuna para los beneficiarios de la reforma agraria, afectan particularmente a la mujer. Aunque en los países considerados prácticamente son inexistentes las estadísticas desagregadas por sexo de beneficiarios de la reforma agraria, la exigua información disponible permite aducir que el impacto de la reforma agraria sobre el acceso a la tierra en todos los países considerados ha sido mayor para los hombres que para las mujeres. $^{7}$

En el marco de otras instituciones internacionales, como la Organización Panamericana de la Salud, se ha diagnosticado que existen restricciones legales o sociales que impiden que muchas mujeres posean o hereden tierra, derecho al agua o a ganado, a la obtención de préstamos o a tomar decisiones sobre el uso de los bienes familiares. Esto repercute negativamente y perjudica su capacidad para administrar la producción y la

\footnotetext{
${ }^{4}$ No puede entenderse intrascendente el hecho de que en Cuba, estando dotadas las autoridades del Ministerio de la Agricultura de las facultades para resolver los conflictos agrarios, a lo largo de más de cinco décadas solo ha desempeñado el cargo de Ministro de la Agricultura y de Presidente del Instituto Nacional de la Reforma Agraria, una sola mujer - por un breve período y con carácter interino- entre una cifra de más de 10 responsables de tales organismos, y no se han designado mujeres para el cargo de Delegado Territorial del Ministerio de la Agricultura.

${ }^{5}$ Ver la Ley de Reforma Agraria venezolana de 5 de marzo de 1960, Gaceta Oficial, Número 611, Edición Extraordinaria, de 19 de marzo de 1960, Caracas, Venezuela.

${ }^{6}$ Ver la Ley 1715 de 15 de octubre de 1996, del Servicio Nacional de Reforma Agraria, La Paz, Bolivia, octubre de 1996.

${ }^{7}$ Galán, Beatriz B.: Aspectos jurídicos en el acceso de la mujer rural a la tierra, en Cuba, Honduras, Nicaragua y República Dominicana.
} 
seguridad alimentaria. Ocupan un lugar insoslayable en la seguridad alimentaria: producen una cifra alimentos, en las parcelas de autoconsumo, huertos, (se ocupan del cuidado de animales domésticos, ordeño de las vacas y cabras) (planifican y deciden en cuanto a los alimentos a consumir cada día), preparan los alimentos y se aseguran (de su calidad y variedad, formar hábitos alimentarios) que llegue a cada miembro de la familia, dedican tiempo y esfuerzos a preparan los ingredientes (condimentos) a acarrear el combustible) ${ }^{8}$

De acuerdo con una investigación realizada en la comunidad indígena de Telolotla hay una marcada diferencia en la asignación de herederos para las tierras privadas y para la parcela ejidal. En el caso de las tierras privadas, de ser suficientes, todos los hijos heredan independientemente de su género, aunque cabe aclarar que las mujeres, en general reciben menos tierras que los hombres. Sobre la interrogante en torno a las lógicas de herencia el particular, 11 encuestados de $30(38 \%)$ opinaron que la tierra se debe transmitir en herencia a todos los hijos; 4 (13.8\%) a todos los hijos hombres, 2 a la mujer y los hijos, 2 al hijo menor, uno al hijo mayor y $9(31 \%)$ no contestaron la pregunta. ${ }^{9}$

El hecho de que en las leyes de reforma agraria, se hayan empleado los aludidos términos genéricos y no se aluda expresamente a hombres y a mujeres, tal vez tenga como fundamento, las tradiciones, la cultura de la época y a factores también geográficos. Como se sabe la alusión expresa a hombres y mujeres es un fenómeno más bien reciente y que aun no goza de generalidad en todo el discurso jurídico; sin embargo, cabe pensar que la intención de sus legisladores era la de beneficiar también a las mujeres campesinas; pero sí se puede dudar de que los resultados fueran precisamente los esperados, por aquello de que con mayor o menor distancia en cada país hubo siempre un espacio entre la letra de las leyes de reforma agraria y su ejecución; margen de tiempo y margen de intensidades.

En segundo lugar, es justo apreciar una tendencia en el Derecho Agrario latinoamericano a reconocerle prioridad al cónyuge supérstite en cuanto al derecho a adjudicarse la tierra, en este mismo sentido resulta visible que varias leyes agrarias dictadas en Latinoamérica se han pronunciado por amparar que en caso de herencia de la tierra o a la transmisión del derecho de usufructo, preferentemente se escoja al heredero más idóneo para

\footnotetext{
${ }^{8}$ OPS: Hoja informativa del Programa Mujer, Salud y Desarrollo, GenSalud, OPS, 2001.

${ }^{9}$ Ver Diego Quintana, Roberto: Lógicas de herencia y derechos sucesorios de la tierra en la comunidad de Telolotla de la Sierra Norte de Puebla. Este trabajo es un producto parcial de una investigación sobre historia agraria, tierra adjetivada y mercado de tierras en una comunidad indígena llamada Telolotla de la Sierra Norte de Puebla, es presentado por un profesor investigador del Departamento de Producción Económica y de la Maestría en Desarrollo Rural; Coordinador del Área de Desarrollo Rural del Doctorado en Ciencias Sociales de la UAMXochimilco, el proyecto de investigación global abarca el estudio de la historia agraria, de la tierra adjetivada y de los mercados de tierras en 10 ejidos de la República Mexicana. En el participaron más de 10 investigadores y está siendo realizado bajo convenio entre la UAM-Xochimilco y el FIFONAFE
}

R. Fac. Dir. UFG, v. 37, n. 2, p. 259 - 281, jul. / dez. 2013

ISSN 0101-7187 
continuar explotando la tierra y para conservar su status productivo. En este sentido vale ilustrar como la Ley Federal de Reforma Agraria, de México, de 1915 establecía una especie de sucesión legítima forzosa en los derechos del ejidatario a favor de la mujer casada y un orden sucesorio que comienza con el cónyuge e hijos y continua, a falta de éstos en la persona con la que el ejidatario haga vida marital (DÍAZ; CABRERA; PAVO, 1998, p.14). Y una regla similar se aprecia en la Ley de Reforma Agraria de Honduras, de 1ro de enero de 1975 en su artículo 84, en la cual se estableció que al fallecimiento del adjudicatario de un predio, tendrán derecho preferente al mismo, la esposa compañera de hogar o algunos de sus hijos que reúnen los requisitos para ser adjudicatario (DÍAZ; CABRERA; PAVO, 1998, p.13).

Las experiencias en el desarrollo doctrinal, en la creación y aplicación del Derecho Agrario en la búsqueda de realización de los fines del Derecho Agrario, a saber: el desarrollo agrícola y el desarrollo rural sostenible, la seguridad alimentaria y la soberanía alimentaria, permiten identificar entre los presupuestos fundamentales para lograrlo, en cuanto al ámbito del Derecho de la propiedad agraria, el que Derecho Agrario, garantice:

La flexibilidad y amplitud en cuanto al grado de los parientes con derecho a la adjudicación por herencia, el enfoque de género, la prioridad en el requisito de dedicarse a alguna de las actividades agropecuarias vinculadas a la finca del propietario que fallece, unido al de parentesco, y la flexibilidad en las formas de acreditar la condición de hijos y cónyuges, apartándose de la rigidez del Derecho Civil, a los efectos de lograr la justicia y la equidad de manera que se asegure, la equidad, la justicia, y la continuidad y la explotación eficiente de la tierra. La noción de parientes, que la ley respalde a los efectos de la herencia de los bienes agropecuarios, debe corresponderse con la concepción de familia propia del medio rural, según los criterios aportados por la Antropología y la Sociología Rural. Ignorar o menospreciar este aspecto puede ser causa de: inseguridad alimentaria, pobreza rural y marginación de los hombres y especialmente de la mujer del campo, inequidad de género, injusticia y violencia social y familiar en el medio rural, entre otros males.

Con respecto de este último aspecto vale la pena subrayar que, una de las claves importantes para el desarrollo rural sostenible, sigue siendo la regulación adecuada de los requisitos y de los procedimientos para la transmisión hereditaria de la tierra, los cuales deben proyectarse hacia asegurar continuidad y la explotación eficiente de la tierra, y para lograr ese propósito, las normas jurídicas tienen que corresponderse con las realidades y aspiraciones del hombre del campo, con su mundo objetivo y subjetivo.

Otro de los presupuestos residen en establecer con claridad y por vía legal la definición de los términos tierras o fincas rústicas, bienes agropecuarios, productos R. Fac. Dir. UFG, v. 37, n. 2, p. 259 - 281, jul. / dez. 2013 
agropecuarios, todo ello a partir del concepto de actividad agropecuaria que es el que posibilita el logro de la unidad sistemática en toda la legislación agraria.

En este sentido, vale remarcar que un presupuesto imprescindible para asegurar la justicia y adecuada construcción sistemática del Derecho en este ámbito lo constituye la noción de actividad agropecuaria. El destacado agrarista argentino Rodolfo Ricardo CARRERA ofrecería ya en 1948, un concepto que sería la base, décadas después, de una nueva teoría sobre el objeto y la construcción sistemática del Derecho Agrario, y transitivamente, de la llamada Escuela Moderna del Derecho Agrario, ya en los años 70, al decir que, "La actividad agraria la constituyen aquellos actos que el hombre realiza en la tierra por medio de una explotación que se cumple a través de un proceso agrobiológico con el fin de obtener de ella frutos o productos para consumirlos, industrializarlos o venderlos en el mercado" (CARRERA, p.129).

La producción agropecuaria en uno de sus sentidos, constituye el proceso mismo realizado por el hombre, para a partir de semillas o embriones, aprovechando ciertos recursos naturales (clima, suelo, agua, etc.) obtener frutos vegetales o animales, por tanto se conforma por un conjunto de actos que irían básicamente desde la siembra hasta la cosecha del producto, constituyendo lo que en él ámbito de las Ciencias Agrícolas se denomina la producción vegetal, que sería lo que entre los juristas se denomina como la actividad agropecuaria principal. Por tanto la transformación, comercialización y transportación del producto, que se califican como actividades agropecuarias conexas o afines, no pueden subsumirse en el concepto de producción agropecuaria, ${ }^{10}$ ni en el de explotación agropecuaria (BRUNO, 2002, p.53).

De tales premisas, pudiera derivarse que existen dos aspectos esenciales - en los cuales se centrará el análisis más adelante-, a los que debe atenderse para asegurar la justicia y equidad de género en el régimen de propiedad y herencia de la tierra: 1) el derecho del cónyuge a la adjudicación por herencia de la tierra y la extensión de este derecho a situaciones análogas, por razones de equidad y justicia, y 2) la extensión del requisito de trabajo en el predio a todas las labores enmarcadas dentro de la noción amplia de actividad agropecuaria.

\footnotetext{
${ }^{10} \mathrm{He}$ defendido en varios trabajos una concepción de la actividad agropecuaria todavía más amplia, que incluya a otros tipos de actividades conexas como la contabilidad, la gestión administrativa y financiera (trámites ante las oficinas bancarias, ante la empresa de seguro, oficinas tributarias, Ministerio de Trabajo e Instituto Nacional de Seguridad Social, Oficinas de Cobros de Multas, Policía Nacional, y otras más. Igualmente merecen el calificativo de agropecuarias las actividades que realizan las mujeres en la finca, de elaboración y distribución diaria de alimentos al campesino y a los trabajadores del campo, lavado de la ropa de ellos, atención habitual del jardín, del huerto, o a los animales domésticos (alimentación, cuidados médicos veterinarios, etc.)
} 


\section{Visión de género y derechos de la mujer a herencia y tenencia de la tierra en la legislación agraria cubana.}

Ley de Reforma Agraria, con ese carácter integral que la definió, se encausó hacia la eliminación o al menos la atenuación de otras desigualdades sociales al proyectarse en cuanto a que los campesinos tuvieran mayor acceso al crédito, a las tecnologías y en cuanto al mejoramiento de las condiciones de vida de la comunidad rural, por eso resulta significativo que la Ley se haya promulgado en La Plata, un recóndito sitio de la Sierra Maestra, ámbito donde la aparcería, el precarismo, los desalojos, el atraso social y cultural del campesino y otras injusticias habían sido precisamente más acentuadas.

Otra de las dimensiones que se destacan en esa ley es la que tiene que ver con los cambios en la situación jurídica de la mujer. Ciertamente la ley en su texto no hace distinción entre hombres y mujeres, a la hora de considerar como beneficiarias a las mujeres campesinas. A esos efectos la ley en su artículo 18 hablaba de adjudicar gratuitamente a los que cultivaran la tierra en condición de colonos, subcolonos, arrendatarios, subarrendatarios, aparceros o precaristas. ${ }^{11}$

Por eso hoy habiendo transcurrido más de 40 años de su promulgación no pueden entenderse como casuales algunas circunstancias concurrentes, como que el primer título de propiedad otorgara al amparo de dicha ley aparece firmado por el Dr. Fidel CASTRO RUZ, entonces Presidente del Instituto Nacional de Reforma Agraria, a favor de la Señora Engracia BLET, adjudicándole a su favor una parcela era parte de la Hacienda Duaba Arriba o Toa, situada en el Barrio Toa, término municipal de Baracoa.

Sobre este hecho, en primer lugar, debe llamar la atención que no parece casual el haber escogido este sitio, si se recuerda que por la parte oriental de la isla comenzó la conquista, con el consiguiente despojo por parte de los conquistadores de la tierra que ocupaban los indígenas, la apropiación desordenada y el acaparamiento de la tierra; en uno de los parajes más atrasados de Cuba y en un municipio prácticamente aislado del resto del territorio nacional. $^{12}$

Aunque entonces, no se explicó el por qué escogió a una mujer, sin embargo al parecer tampoco fue fortuita esa circunstancia, teniendo en cuenta la situación de desigualdad

\footnotetext{
${ }^{11}$ Ley de Reforma Agraria, de 17 de mayo de 1959, Gaceta Oficial, Edición Extraordinaria, Número 7, 3 de junio de 1959.

${ }_{12}$ Es así que si se observa la fotografía que publicó el Periódico Revolución en la época se verá que la beneficiada tenía rasgos fisonómicos que indiscutiblemente delataban sus ancestros de la raza originaria. Ver Núñez Jiménez, Antonio: En Marcha con Fidel, Tomo I, p. 413.
}

R. Fac. Dir. UFG, v. 37, n. 2, p. 259 - 281, jul. / dez. 2013 
y de discriminación de la mujer, pudiendo entenderse el hecho como simbólico, programático, que marcaría el inicio de una nueva política agraria y todavía más: de una nueva política social. Como ese caso existieron muchos otros en los que se le reconoció individualmente el derecho de beneficiaria de la ley a muchas mujeres. ${ }^{13}$

Luego hubo otra Ley, el 3 de octubre de 1963, conocida como Segunda Ley de Reforma Agraria, que nacionalizó todas las fincas mayores de 5 caballerías, 67 hectáreas, teniendo como una de sus excepciones a las fincas que estuvieran siendo trabajadas por varios hermanos, siempre que la parte proporcional de la extensión de dichas fincas que corresponda a cada hermano participante en la explotación, no exceda de 67 hectáreas y 10 áreas (5 caballerías). ${ }^{14}$ Poco después se aclaró mediante una carta del Presidente del INRA en 1963, que la misma excepción se aplicaría a los casos de fincas trabajadas conjuntamente por padres e hijos si su cuota proporcional no excedía del referido límite. ${ }^{15}$

A este mismo respecto, vale la pena precisar que el propio texto de la Ley de 17 de mayo de 1959 y su aplicación también condicionarían una situación de falta de paridad de género en cuanto al derecho de la mujer a ser adjudicataria de la tierra con motivo de la herencia, pues el artículo 35 de dicha Ley, reguló que, "Las nuevas propiedades se mantendrán como unidades inmobiliarias indivisibles, y en caso de transmisión hereditaria deberán adjudicarse a un solo heredero en la partición de bienes (...).” En este precepto la Ley evidentemente defiende varios principios del Derecho Agrario: el principio de indivisibilidad de la tierra, el de la conservación de la situación productiva de las fincas, especialmente de la pequeña propiedad y el de que, por tanto su adjudicación se realice sólo a favor del heredero más idóneo para continuar explotando la tierra de la forma más eficiente, de lo cual deriva también una proyección a favor de herederos del sexo masculino, pues no debe olvidarse que se trataba de un contexto cultural marcado por el androcentrismo.

\footnotetext{
${ }^{13}$ Ver artículos 1 y 2 de la Ley de nacionalización de fincas mayores de 67 hectáreas y 10 áreas, de 3 de octubre de 1963, Gaceta Oficial, Edición Extraordinaria Especial, Número 1, de 3 de octubre de 1963. Pero como en la aplicación de esta ley no existió un riguroso proceso de titulación y de registro de las tierras otorgadas, sucedió luego que al crearse los registros de tenencia de la tierra en 1987, las tierras de los beneficiarios de la ley se inscribieron, a través de declaraciones juradas, y por lo general sólo a nombre de los interesados - en su gran mayoría a los hombres -, que acreditarian haber tenido la condición de arrendatarios, colonos, o precaristas al momento en que se dictó la ley en 1959 y no como una copropiedad con sus esposas o compañeras del hogar.

${ }^{14}$ Ver Ley de 3 de octubre de 1963, Edición Extraordinaria Especial, Número 1 de 3 de octubre de 1963. Ver artículos 1 y 2 .

${ }^{15}$ Aquí debe haber sucedido más o menos lo mismo explicado anteriormente para la primera ley, pues la segunda ley no tuvo un pronunciamiento expreso en cuanto al caso de hermanas, madres o hijas, y por tanto, en la práctica quedarían como no afectadas mayormente las fincas trabajadas padres e hijos, del sexo masculino, este hecho explicaría las razones por las que en los 90, los dueños de fincas en la casi totalidad de los casos, eran hombres y no mujeres, tal y como pude apreciar en mi investigación doctoral, Mecanismos y procedimientos de solución de reclamaciones y conflictos agrarios.
}

R. Fac. Dir. UFG, v. 37, n. 2, p. 259 - 281, jul. / dez. 2013

ISSN 0101-7187 


\section{El requisito de trabajar la tierra bajo el enfoque de género.}

La Constitución de la República, promulgada el 24 de febrero de 1976, en su artículo 24 consagró el principio de que "la tierra propiedad de los agricultores pequeños fallecidos sólo puede ser heredable por aquellos herederos que la trabajen personalmente, salvo las excepciones que establece la ley" 16

Dicho precepto legitima constitucionalmente el régimen especial de la herencia de la tierra y bienes agropecuarios, sustrayéndolo del dominio del Derecho Civil y trasladándolo hacia el Derecho Agrario. Pero la dicción de este precepto, probablemente -al menos parcialmente-, sea responsable de los dilemas interpretativos y frecuentes conflictos a los que ha dado lugar, pues literalmente alude al trabajo personal en la tierra, en cuyo concepto sólo cabe la actividad agropecuaria principal, quedando fuera las conexas, y otras muchas que son las que normalmente realiza la mujer del campo.

Este problema se mantendría bajo el Decreto- Ley 63, Sobre la herencia de la tierra propiedad de agricultores pequeños de 30 de diciembre de 1982, el que en su artículo 1 dispuso que, "Los herederos legítimos con derecho a la tierra propiedad y en posesión de un agricultor pequeño fallecido serán aquellos, declarados judicialmente, que la hayan trabajado en forma permanente y estable desde un año antes del fallecimiento del causante y los que hayan arribado a la edad laboral dentro de ese termino. ${ }^{17}$

Por su parte la Resolución 324 de 1983, que fue el Reglamento del mencionado Decreto- Ley 63, definió en su artículo 1 que a esos efectos se entenderá por "trabajar en forma permanente y estable: los que trabajan personalmente la tierra durante todo el ciclo de producción agropecuaria a la que está dedicada la misma, teniendo una participación fundamental en los ingresos obtenidos." 18 Por lo que puede verse que el discurso de la aludida resolución resultaba todavía más restrictivo, y por tanto menos inclusivo de trabajo de la mujer, dejando muy poco espacio para la paridad de género a este respecto.

Adelardo Martín Alba, quien se desempeñara durante muchos años como Director Jurídico, primero del INRA y luego del Ministerio de la Agricultura, advertía sobre este peligro cuando señalaba:

\footnotetext{
${ }^{16}$ Constitución de la República de Cuba, aprobada el 15 de febrero y promulgada el 24 de febrero de 1976.

${ }^{17}$ Decreto-Ley 63, Sobre la herencia de la tierra, Gaceta Oficial, Edición Especial, Número 9, 30 de diciembre de 1982. (Derogado por el Decreto Ley 125 de 1991).

18 Resolución 324, Reglamento del Decreto Ley 63, del 2 de noviembre de 1983, del Ministerio de la Agricultura, Gaceta Oficial, Edición Extraordinaria Especial, Número 79. (Derogada por la Resolución 24 de 18 de marzo de 1991).
}

R. Fac. Dir. UFG, v. 37, n. 2, p. 259 - 281, jul. / dez. 2013 
Así por ejemplo al considerar lo que determina el artículo 1 del Decreto Ley 63, sobre el derecho que le asiste al heredero que trabaja la tierra en forma permanente y estable, si lo hacemos desde el punto de vista literal del artículo y no lo analizamos en función de lo que en si fue su objetivo, podríamos cometer una injusticia, al no considerar con derecho a la tierra a herederos que realizan en forma permanente y estable, otras labores que integran el contenido de trabajo a realizar en una unidad de producción agropecuaria, como son los quehaceres domésticos, la atención de los animales y otras que son necesarias y hasta imprescindibles para el que trabaja directamente la tierra haciéndola producir. ${ }^{19} \mathrm{Y}$ continuaba expresando MARTÍN ALBA que, "Como se puede apreciar la interpretación errónea (...) desvirtúa el real propósito para el que se concibió el precepto". (ALBA, 1987, p.12)

La legislación vigente sobre la adjudicación de la tierra en caso de fallecimiento del agricultor pequeño - Decreto Ley 125 de 1991-, dispone que, “Tendrán derecho a heredar la tierra y bienes agropecuarios que hayan sido propiedad y estado en posesión de un agricultor pequeño fallecido y a su adjudicación en proporciones iguales, sus hijos, padres, hermanos, y el cónyuge sobreviviente, siempre que hayan trabajado la tierra en forma permanente y estable desde cinco años antes de la muerte del causante". ${ }^{20}$ En su artículo 2, inciso a) regula que, "Es trabajo permanente y estable en la tierra: el trabajo personal que se realice habitualmente y en forma continuada según los requerimientos de la producción agropecuaria a la que esté destinada la tierra y cualquier otro relacionado con la atención de la tierra que resulte necesaria." 21

A ello se debe agregar que este Decreto Ley establece el derecho de esas personas relacionadas en el mencionado artículo 18 a recibir el precio de la tierra cuando no cumplen el requisito de trabajo permanente, careciendo de ingresos propios y dependían económicamente del trabajo de la finca. Y de acuerdo con este Decreto- Ley la decisión sobre la actio hereditatis, en cuanto a tierra y bienes agropecuarios pertenecientes al pequeño agricultor que fallece, es facultad de los funcionarios del Ministerio de la Agricultura.

Entonces, lógicamente, el aludido precepto contenido en el artículo 2-c del Decreto Ley 125 - al remitir al concepto de producción agropecuaria para definir trabajo permanente-, ha estado generando infinidad de problemas interpretativos, conflictos, y potencialmente, puede dar lugar a injusticias a la hora de decidir quiénes son los herederos de la tierra y demás bienes agropecuarios que han pertenecido al pequeño agricultor que fallece, pues la interpretación literal conduce inevitablemente a que los herederos son personas que

\footnotetext{
${ }^{19}$ Martín Alba, Adelardo: "Compendio de la legislación agraria cubana", p. 12.

${ }^{20}$ Decreto- Ley 125, de 30 de enero de 1991, Régimen de posesión, propiedad y herencia de la tierra y bienes agropecuarios, Gaceta Oficial Edición Extraordinaria, Numero 1, 30 de enero de 1991.

21 Ibídem
} 
realizan una actividad agropecuaria de carácter principal, no así los que realizan labores conexas.

Resulta evidente que existe cierta zona o área que define los alcances de la norma en cuanto al concepto trabajo permanente y estable, que aparece nítidamente muy definida, en la que se incluirían con toda claridad, la siembra, las labores de roturación del terreno, la limpia, fertilización, fumigación y la cosecha. El problema es que en una finca habitualmente, existen parientes que realizan otras labores, como la transportación (traslado de los productos obtenidos en la finca hacia el mercado, o de envases e insumos productivos), comercialización (venta de los productos de la finca en un punto dentro del propio predio o en el mercado más cercano), beneficio (lavado, secado, trillado, envasado), transformación (elaboración de jugos, dulces, condimentos, queso, a partir de los propios productos de la finca); actividades en las que se involucran muy particularmente las mujeres (cónyuge, madre, hijas y hermanas del fallecido), labores que resultan de indiscutible importancia dentro del ciclo de realización de la actividad agropecuaria, siendo evidente que todas estas personas que las realizan, hoy no encuentran la debida protección jurídica en la letra de los preceptos ya citados de la Constitución y del Decreto Ley 125, lo cual es causa inseguridad jurídica respecto a su derecho a la herencia, dando lugar en este sentido a una falta de unidad interpretativa en los diferentes territorios del país, y en consecuencia, también se quiebra la justicia y la paridad de géneros.

Así por ejemplo, ante un caso en el cual habiendo fallecido el propietario de una finca, (cuya línea fundamental de producción sea el café, frutales o la ganadería) donde reclaman tener derecho a la herencia, su hijo de 30 años de edad que acredita haber trabajado la tierra junto a su padre los últimos 10 años y su viuda de 55, la que acredita haberse dedicado a las labores del hogar, al cuidado de los animales domésticos y haber participado en la cosecha sobre todo en sus momentos pico. Ante este caso que frecuentemente se presenta ante los funcionarios y especialistas del Minagri, tales operadores jurídicos han asumido dos soluciones: una primera consistente en darle derecho a la tierra únicamente al hijo, otorgándole a la viuda solamente el derecho al precio de su parte proporcional, y la otra solución que es la de reconocerle el derecho a ambos otorgándole la finca en copropiedad. Como puede apreciarse se trata, de una primera solución más rígida, apegada a la letra de la legislación y una segunda más flexible e inclusiva en cuanto al derecho de la mujer.

Se debe partir del hecho de que ciertamente las referidas normas presentan una textura bastante abierta y ofrecen amplias posibilidades de arbitrio, rasgo que es propio de las normas de Derecho Agrario, precisamente para favorecer la realización del principio de R. Fac. Dir. UFG, v. 37, n. 2, p. 259 - 281, jul. / dez. 2013 
justicia agraria, y eso es positivo, ahora bien, esos preceptos crean la base de cierta inseguridad jurídica, al no poder preverse con certeza cuál sería la decisión que adoptarán ante el caso las autoridades agrarias. De todos modos, resulta notoria la carencia de una regulación más abarcadora en el concepto de trabajo permanente, sobre todo cuando se trata de una mujer, presunta heredera de la tierra que era propiedad del agricultor fallecido, en este caso, la viuda, hermanas, hijas o la madre del causante.

En el hecho de que no siempre se adopten soluciones adecuadas a estos casos, pudiera estar influyendo una mixtura de factores de diversa índole. Entre los de orden legislativo cabe señalar que la legislación vigente en materia procesal adjetiva agraria no contiene regulaciones expresas sobre los principios y fines de la jurisdicción en asuntos agrarios, ni sobre la definición de actividad agropecuaria. Estos problemas serían solubles, en primer, lugar, modificando la norma, y hablando únicamente de "actividad agropecuaria" en vez de "producción agropecuaria" y de "explotación agropecuaria" y construir a partir de este concepto el requisito de trabajo en la finca.

$\mathrm{Y}$ en el orden institucional cabe considerar que tampoco resulta favorable la concepción del mecanismo de solución de los conflictos agrarios, a los efectos de que las decisiones resulten un modelo de justicia, calidad técnica y realismo. Es decir que la decisión constituye una potestad de un funcionario administrativo, que normalmente no es abogado, y que no siempre posee conocimientos suficientes de Agronomía, Sociología Rural y Economía de la Agricultura, y ocurriendo que no siempre el asesoramiento jurídico con que cuentan tales funcionarios decisores, se efectúa con toda la calidad requerida a causas de diversas razones, apreciables con mayor o menor intensidad en unos territorios que en otros: falta de completamiento, e inestabilidad, la juventud y falta de años de experiencias, la sobrecarga de trabajo, insuficiente formación de postgrado del personal jurídico asesor, insuficiente nivel de control y exigencia administrativa del rigor en el procedimiento probatorio. ${ }^{22}$

Es comprensible que el logro de soluciones justas para estos caso no resulte tarea sencilla, debido a los factores objetivos y subjetivos incidentes, por eso tal vez no todo deba confiarse a la legislación, pues también harían falta cambios en el entorno, lo que incluye

\footnotetext{
${ }^{22}$ Algunas de las deficiencias fueron advertidas dentro de los límites del marco de experiencia de este autor y otras fueron objeto especifico de la investigación empírica que sirvió de soporte a la Tesis doctoral a la que ya he aludido anteriormente en esta exposición y reanalizadas en otros trabajos. Ver Pavó Acosta, Rolando: Los justicia agraria y sus desafíos, p. 163.
} 
avanzar un poco más en contar una buena dosis de un pensamiento flexible, despojado de mecanicismos, patrones culturales asumidos y prejuicios de género. ${ }^{23}$

\section{El problema de género en cuanto a la situación del cónyuge o compañero del hogar en ocasión de la herencia de la tierra.}

Como ya se enunció, el artículo 18 del Decreto Ley 125, incluye al cónyuge, entre las personas que deben ser llamadas a heredar la tierra y demás bienes agropecuarios, y conforme a la noción estricta del Derecho Familiar, son cónyuges, los miembros de la pareja unida legalmente en matrimonio, y en consecuencia, tal condición sólo puede ser acreditada mediante certificado de matrimonio otorgado por el Registro del Estado Civil o en su caso, la condición de excónyuge cónyuge sobreviviente, que sería acreditada por una sentencia donde se reconozca que hubo una unión matrimonial entre ese cónyuge sobreviviente y el otro cónyuge que ha fallecido, desde un determinado tiempo y hasta el momento en que se produce el fallecimiento de uno de esos cónyuges.

Por ello, resulta ajustado a la ley - a la noción del concepto "cónyuge" que refrenda el referido artículo 18 del Decreto- Ley 125-, que en las reclamaciones presentadas por el presunto cónyuge del agricultor pequeño que fallece, las autoridades del Ministerio de la Agricultura que deben resolver, le exijan a esa persona el reconocimiento judicial de matrimonio, pero en la práctica complica bastante la tramitación de muchos expedientes, afectándose el principio de celeridad y suele quebrar también la justicia y la equidad de géneros, pues, en caso de existir conflictos entre los hijos y la viuda, éstos que, por supuesto van a ser parte en el proceso civil de reconocimiento del matrimonio, cuentan con todo un repertorio de medios procesales para impedir que la viuda obtenga sentencia favorable del tribunal en cuanto a que se le reconozca el matrimonio, lo cual crea bastante incertidumbre respecto a cómo va a ser el fallo del juez, a ello se suma que tal reconocimiento tendría que referirse claramente a los cinco años anteriores al fallecimiento del causante, el resultado ha sido que en muchos casos, la viuda queda privada de los derechos de herencia a la tierra y demás bienes agropecuarios.

\footnotetext{
${ }^{23}$ Resulta curioso que durante el ejercicio de docencia con estudiantes de cuarto y quinto año de la carrera de Derecho y también con abogados de ejercicio, como alumnos de postgrado, en innumerable ocasiones he indicado a dichos alumnos la solución de casos como el de examen, y en la casi totalidad de las veces independientemente del sexo de los alumnos-, la solución que ofrecen es la primera aludida, digamos que la más rígida, es decir, la que no le da derecho a la tierra a la mujer. Lo que indica que también habría que continuar trabajando en la formación de los valores correspondientes en los futuros graduados y en los juristas en ejercicio.
} 
Pero la compulsión a la viuda reclamante a probar documentalmente su condición resulta cuestionable desde el punto de vista de la Sociología y la Antropología, pues diversas investigaciones han acreditado que en las zonas rurales de Cuba ha predominado la baja nupcialidad y la alta consensualidad como el patrón histórico de formación de la familia (MOREIRA, 1990, p.60).

A este respecto, resulta pertinente recordar que la Ley 3, de 10 de octubre de 1958, es decir, dictada todavía en plena contienda insurreccional, en su artículo 23 en relación con el 9, le daba derecho a la adjudicación por herencia de la tierra propiedad de un beneficiario de esta Ley a la mujer unida extramatrimonialmente con el causante de forma estable que hubiera convivido con él durante al menos un año ${ }^{24}$. Resulta difícil de comprender que al cabo de casi cincuenta años la legislación haya ido en retroceso y sólo le conceda el derecho a la viuda de matrimonio formalizado o reconocido judicialmente. Ya la legislación agraria de varios países de América Latina ha ido asumiendo un criterio amplio y flexible a este respecto, inclusive en Cuba la legislación sobre Seguridad Social admite desde hace varias décadas el derecho de la viuda del trabajador que fallece a obtener la pensión, sin exigírsele haber estado casada ni reconocer judicialmente el matrimonio con el fallecido.

Y si en las zonas rurales del país existe una alta consensualidad, o sea las parejas normalmente no formalizan el matrimonio, el asunto de la justicia no se resuelve con que el Derecho deje sin protección ante la herencia al miembro de esa pareja que sobrevive como receta social para compulsar al matrimonio formalizado, parecería una reminiscencia burguesa, hoy ya muy fuera de contexto y tampoco, como ya se ha dicho, resulta una buena solución el obligar al cónyuge supérstite a que vaya al trámite judicial de reconocimiento de la unión matrimonial, con el único propósito de adjudicarse la tierra.

El gobierno cubano conciente del problema de la alta consensualidad y de las complicaciones jurídicas que puede acarrear por la manera en que están concebidas las normas laborales, de seguridad social, de propiedad, sucesiones etc., ha aplicado paliativos. Acabando el año 1959, de acuerdo con una iniciativa impulsada por el entonces Ministro de Justicia Alfredo Yabur Maluf, se procedió a una intensa campaña para que miles de parejas de hecho pudieran contraer matrimonio civil, sobre todo en las áreas rurales, en lo que dio en llamarse “Operación Matrimonio" (RODRÍGUEZ; SUÁREZ, 2002, p.160). Sistemáticamente este organismo ha seguido organizando campañas encaminadas a formalizar de manera colectiva los matrimonios en numerosas comunidades rurales; pero obviamente todo no ha

\footnotetext{
${ }^{24}$ Ver Ley 3, Sobre el derecho de los campesinos a la tierra, de 10 de octubre de 1958, en Valdés, Orlando: Historia de la Reforma Agraria en Cuba, p.146-156.
}

R. Fac. Dir. UFG, v. 37, n. 2, p. 259 - 281, jul. / dez. 2013

ISSN 0101-7187 
podido resolverse de este modo, si ello no está asentado en las costumbres, la cultura y en los rasgos antropológicos del hombre del campo.

Algo similar se aprecia cuando se exige inexorablemente a los descendientes probar la filiación por los medios que establece el Derecho Civil. Todos los abogados sabemos, -aunque se disponga de datos estadísticos exactos, ni de investigaciones sociológicas cuantitativas y antropológicas actuales en este ámbito- que en los campos resulta frecuente que los padres no reconozcan legalmente a los hijos, e hijas y que éstos tampoco reclamen oportunamente el reconocimiento de la filiación, lo cual constituye un reflejo de la particular concepción que sobre la familia tiene el campesino. ${ }^{25}$

Se ha reiterado por varios agraristas que el Derecho Agrario, es más un Derecho de justicia que de legalidad estricta, a diferencia del Derecho Civil. Por supuesto que la exigencia procesal, de tener que acudir la viuda o viudo, al proceso de reconocimiento de matrimonio pueden generar situaciones de indefensión y de injusticia, en cuanto a la satisfacción de derechos humanos esenciales del hombre del campo y su familia. Ello por supuesto que es base para demoras indebidas en los procedimientos, generando afectaciones a la estabilidad en la situación posesoria en la familia, que constituye uno de los presupuestos insoslayables para alcanzar el desarrollo rural sostenible en las comunidades, al perderse los conocimientos tradicionales, transmitidos de generación en generación, cuestión de alta relevancia sobre todo en muchas actividades agropecuarias sometidas a muy rigurosos manejos técnicos como el café, el tabaco, la caña de azúcar, la ganadería vacuna y otras.

A este respecto el Código de Familia, realiza pronunciamientos bien estrictos, "El matrimonio solo producirá efectos legales cuando se formalice o se reconozca de acuerdo con las reglas establecidas en la Ley del Registro del Estado Civil”, "Los encargados del Registro Civil y los notarios públicos son los funcionarios facultados para autorizar la formalización de los matrimonios". 26

\footnotetext{
${ }^{25}$ Sabemos que el hombre del campo, dice a menudo « esta es mi mujer, este es mi hija », aunque no haya sido procreada por él, pues su esposa ya la portaba cuando viniera a vivir en su compañía desde hace varias décadas, como también reconoce y representa a su esposa ante toda la comunidad, con la misma o probablemente mayor seriedad con que lo asume el hombre de la ciudad aunque este último haya celebrado legalmente su matrimonio y él no. Y suele decir también, « cuando yo muera quiero que todos mis hijos y mi mujer sean dueños por igual, de todo esto que yo les voy a dejar », Obviamente esta noción de familia, entra en colisión con lo que ha sido establecido por las normas civiles tradicionales, y van a venir las autoridades y dirán « los herederos son sólo éstos, y estos otros no pues no tienen acreditada su filiación, y esta tampoco era su esposa porque no sostuvo un matrimonio legal con el fallecido». Y ahí comenzaría un conflicto interminable y que de seguro tendrá al final una solución injusta y puede que hasta fatal, que resquebrajará la unidad de esa familia, y la de la comunidad de vecinos que se polarizará defendiendo el derecho de unos o de otros y en consecuencia, también se afectará el cumplimiento de la función económica y social de la finca.

${ }^{26}$ Ver Artículos 2 y 7 de la Ley 1289, Código de Familia, de 14 de febrero de 1975 (Anotado y concordado) en Pérez Gallardo, Leonardo: Compilación de Derecho de Sucesiones, Volumen 1, pp. 104 y 106.
} 
Pero el propio Código de Familia, flexibiliza el criterio cuando en su artículo 22 dispone que, "En cualquier proceso civil, penal o administrativo en que no pudiera probarse la existencia de la unión matrimonial conforme con la Ley del Registro del Estado Civil, a los fines del proceso de que se trate, hará prueba de sus existencia, la posesión constante del estado conyugal unida a las actas de inscripción de nacimiento de los hijos si los hubiera y con los efectos, según el caso, del artículo $18 .^{27}$

Decía con acierto ese ilustrismo agrarista mexicano que fue Lucio MENDIETA Y NúÑEZ, que "a problemas agrarios, soluciones agrarias"; resultando entonces que este problema requiere de una solución legislativa coherente con los fines y normas del Derecho Agrario y que debe ser precisamente encontrar una fórmula menos apegada a la rigidez del Derecho Civil, más cercana al propio Derecho de Familia, y que pudiera ser, en primer lugar, reconociendo expresamente el derecho a heredar la tierra a la esposa o compañera del hogar del campesino que fallece, y en segundo lugar, que la ley agraria autorice a los funcionarios de la agricultura a no exigir la realización de procesos judiciales previos, para acreditar estado conyugal y en su caso la filiación, nombre correcto, cuando estos extremos no resulten ni litigiosos ni equívocos, estimo que el pronunciamiento, a que se debe autorizar que realice el funcionario, no es el de reconocer el carácter de hijo, esposa o el nombre verdadero, que es una facultad privativamente judicial y del Registro Civil, se trataría solamente de hacer un pronunciamiento de alcances solamente intraprocedimiento, es decir, a los efectos sólo de ese procedimiento agrario especifico. Diría algo así como "que en virtud de las pruebas practicadas en los marcos de este procedimiento, se le reconoce a $\mathrm{C}$ el derecho de viuda de $\mathrm{A}$, o a B, el derecho de hijo de A...", y que por tanto procede que se le adjudique la finca X... “

Pero resulta evidente que no bastaría con cambiar las leyes a este respecto, si en muchos casos prevalece la interpretación de la ley animada por enfoques androcéntricos, por ello como bien propone Beatriz B. GALÁN, habría también que, "Sensibilizar a los funcionarios de los organismos nacionales de planificación, para que en la formulación y evaluación de políticas y programas, introduzcan la perspectiva de género con el fin de lograr una mayor equidad en las oportunidades de participación de las mujeres y hombres en el proceso de desarrollo" 28 , pero también a todos los jueces, y especialmente a los funcionarios administrativos que actúan como operadores jurídicos en el sector agrario (del Ministerio de la Agricultura, de Finanzas y Precios, de Trabajo y Seguridad Social, de los Bancos, de las Empresas de Seguro, y también de las organizaciones sociales de campesinos.

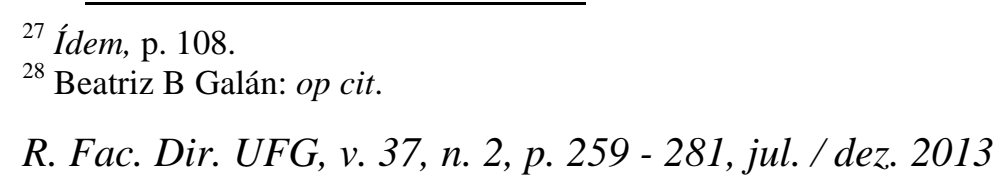




\section{Consclusiones}

Primera: La legislación de la reforma agraria en América Latina ha tendido a reconocer en la letra de sus respectivas leyes, el derecho de la mujer a la tierra y a su adjudicación en caso de herencia, pero lo han hecho de manera muchas veces implícita y no explícita y entonces tal pronunciamiento ha encontrado obstáculos culturales para su eficacia.

Segunda: La legislación agraria cubana exhibe logros indiscutibles en el tema de la herencia dado los niveles de justicia hacia los que se proyecta, no obstante, presenta deficiencias, que afectan el logro de la justicia, la equidad de género y por tanto, la seguridad alimentaria y el desarrollo rural sostenible, consistentes en:

1. Resulta incorrecta la regulación del requisito de trabajo permanente y estable en el Decreto Ley 125 de 1991, en el sentido de que su redacción resulta poco inclusiva de las labores que normalmente realiza la mujer campesina, a los efectos de respaldar su derecho a la tierra en los casos de herencia.

2. Regulación incorrecta del requisito de parentesco en el caso de la viuda o viudo, al emplear el concepto de cónyuge, que resulta de uso exclusivo sólo para los casos en que existe matrimonio formalizado o reconocido judicialmente y por tanto, el precepto no es inclusivo de los numerosos cao en que las uniones no disfrutan de ese requisito legal.

Tercera: Existen deficiencias en los operadores de la normativa agraria, consistente en que en ocasiones se interpreta y aplica de manera rígida el requisito de trabajo permanente y estable, lo que repercute en que no se le reconozca el derecho de la mujer a la tierra en situaciones que positivamente debería corresponderle este derecho, lo cual no se corresponde con el verdadero rol que desempeñan muchas mujeres en los sistemas productivos y en el logro de la seguridad alimentaria

Cuarta: La preocupación por hacer que la tierra cumpla con su función social, puede y debe compatibilizarse con el principio de justicia agraria, y con el principio constitucional de igualdad por razón de sexo, sobre todo porque el sexo no es una condición sine quanon para hacer que la tierra cumpla con su función productiva, no debiendo olvidarse que la propiedad de la tierra, es una propiedad especial que cumple otras funciones de interés familiar y comunitario, al ser la base del disfrute del derecho a la vivienda y a una vida digna, de ahí el celo que se requiere para resolver bien un conflicto de este tipo, para que no queden afectados el desarrollo sostenible de la agricultura familiar, el desarrollo rural sostenible y la seguridad alimentaria a nivel de la comunidad rural y a nivel nacional. 


\section{Recomendaciones}

Primera: A las Facultades de Derecho, Que resulta necesario continuar trabajando en la formación y consolidación de valores en los estudiantes y juristas, particularmente en lo concerniente a la justicia, la paridad de géneros, en la educación de pregrado y de postgrado, lo que repercutirá en una interpretación más adecuada de las normas de lo que resultaran decisiones con mayor grado de calidad y justeza.

Segunda: A las Sociedades Científicas de Derecho Civil, de Derecho Agrario, Derecho Procesal, y a la Unión Nacional de Juristas de Cuba; que deben aumentar los espacios, tales como las sesiones conjuntas de tales sociedades, sobre todo en cuanto a los temas ubicados en las interciencias, como resultan especialmente, los referentes a la seguridad alimentaria y el enfoque de género; con vistas a propiciar un mayor grado de integración de los conocimientos jurídicos entre los juristas.

Tercera: Al Órgano Legislativo, que se debe modificar el Decreto Ley 125 de 1991:

a. En el sentido de introducir los conceptos de "actividad agropecuaria" en vez de "producción agropecuaria" y de "explotación agropecuaria" y construir a partir de ellos, el requisito de trabajo en la finca, asegurando una actitud más inclusiva de las labores que normalmente desempeña la mujer del campo, a los efectos de reconocer su derecho a la tierra y alcanzar mayores niveles de materialización del principio constitucional de igualdad jurídica y equidad de géneros y así propender a la seguridad alimentaria y al desarrollo rural..

b. En el sentido de autorizar a los funcionarios de la agricultura a no exigir la realización de procesos judiciales previos, para acreditar estado conyugal y en su caso la filiación, nombre correcto, cuando estos extremos no resulten ni litigiosos ni equívocos.

\section{Bibliografía}

ACOSTA, Rolando Pavó. Mecanismos y procedimientos de solución de reclamaciones y conflictos agrarios en Cuba. Tesis Doctoral. Santiago de Cuba, 1997. 
ACOSTA, Rolando Pavó. El derecho de la mujer, a la tierra entre la igualdad y la discriminación, Santiago 104, n. 2. Universidad de Oriente. Santiago de Cuba: Universidad de Oriente, 2004. p.160-176.

ACOSTA, Rolando Pavó. Los dilemas procesales del Derecho Agrario en el contexto de su autonomía e interrelaciones con las demás ramas jurídicas. CD ROM. Memorias Científico Metodológicas Derecho Civil y Familia. UO, 2006.

ACOSTA, Rolando Pavó. La Justicia Agraria y sus desafíos, Grupo de Investigación Eumed.net, Biblioteca Virtual de Derecho, Economía y Ciencias Sociales, Universidad de Málaga, España, 2011, Registro: 11/67796. Disponible en <http://www.eumed.net/libros/2011c/1003/index.htm>

ALBA, Adelardo Martín. Compendio de la legislación agraria cubana, Revista Cubana de Derecho. n. 29. La Habana, 1987, p.5-14.

BRUNO, José de Jesús Álvarez. Enfoque sistemático de la noción de tierra y de bienes agropecuarios en la legislación civil y agraria cubana, Tesis de Especialidad de Derecho Civil y de Familia. Santiago de Cuba: 2002.

CABRERA, Freddy Pérez. ¿Y quién trabaja en el campo?, Granma, La Habana, 4 de abril de 2008, p.7.

CARRERA, Rodolfo Ricardo. La teoría agrobiológica del Derecho Agrario y sus perspectivas, Derecho y Reforma Agraria, IIDARA, 12/ 79, Mérida, Venezuela, p. 127-151.

DÍAZ, Estela; CABRERA, Luisa; PAVO, Rolando. Régimen Jurídico de la herencia de la tierra en el Derecho Iberoamericano, Conferencia Científica Provincial de la Organización de Bufetes Colectivos. Santiago de Cuba. Diciembre, 1998.

GALÁN, Beatriz B. Aspectos jurídicos en el acceso de la mujer rural a la tierra, en Cuba, Honduras, Nicaragua y República Dominicana, Organización de las Naciones Unidas para la Agricultura y la Alimentación (FAO), junio de 1999. Disponible por:

<ftp://ftp.fao.org/sd/sdw/sdww/aspectos.zip > y en 〈http://www.fao.org/sd/index_es.htm>

GALLARDO, Leonardo Pérez. Compilación de Derecho de Sucesiones. v. 1. La Habana:

Editorial Minjus, 2008.

HABBA, Enrique P. “Racionalidad y método para el Derecho: es eso posible?”, Doxa, 9/1990, Alicante, España.

MOREIRA, Mayda Reca et al. Análisis de las Investigaciones sobre la Familia cubana 19701987, Centro de Investigaciones Psicológicas y Sociológicas. ACC, Ciencias Sociales. La Habana, 1990.

OPS: Hoja informativa del Programa Mujer, Salud y Desarrollo, GenSalud, OPS, 2001, . Disponible por <http://www/paho.org/generoysalud/>

PÉREZ, José Martí. Hombre del campo, Obras Completas, Volumen XIX, Edición Digital, Centro de Estudios Martianos, 2001, tomada de la Segunda Edición, Ciencias Sociales, La Habana, 1975, p. 380-382. 
REMÓN, Arisbel Leyva. Cambios socioclasistas y relaciones agrarias en la provincia Granma a partir de 1993, Tesis en Opción al Grado Científico de Doctor en Ciencias Sociológicas. La Habana, 2006.

RODRÍGUEZ, Luís María Buch; SUÁREZ, Reynaldo Suárez. Otros Pasos del Gobierno Revolucionario Cubano. 2. ed. La Habana: Ciencias Sociales, 2002.

VALDÉS, Orlando. Historia de la Reforma Agraria en Cuba, Ciencias Sociales. La Habana, 2003.

ZELEDÓN, Ricardo Zeledón. El Derecho Agrario como Derecho para la paz, Discurso académico dictado en la inauguración del Simposio Internacional de Derecho, Justicia Agraria y Ambiental para la Paz, celebrado en Guatemala del 26 al 30 de abril de 1999, organizado por la Unión Mundial de Agraristas Universitarios.

ZELEDÓN, Ricardo Zeledón. Los desafíos del Derecho Agrario, en VI Congreso Mundial de Derecho Agrario, Unión Mundial de Agraristas Universitarios, Almería. España, del 11 al 15 de abril del 2000.

ZELEDÓN, Ricardo Zeledón. Origen, Formación y desarrollo del Derecho Agrario en los Derechos Humanos (Hipótesis para su investigación), en Memorias del Congreso Internacional Derecho Agrario y Derechos Humanos, Cuzco SA. Lima, Perú, 1987.

ZELEDÓN, Ricardo Zeledón. Derecho Agrario Contemporáneo. Objeto, Método, Fuentes e Interpretación (El tridimensionalismo epistemológico), Contemporánea S.A.. San José, Costa Rica, 2011. 